\title{
Influence of Motivational Beliefs on School Learning
}

\author{
Liu Ruiguang \\ School of education and science, \\ Yancheng Teachers' University, \\ Yancheng, China \\ zhl2005112@sina.com
}

\begin{abstract}
In order to make instructors aware of continuous changing of youngsters' psychological needs with motivational beliefs in relation to learnings, let them provide students with a favorable learning context. A synthesis of principles of motivational beliefs that stem from studies aimed at investigating the association between motivation and learning outcomes is made in this paper. A detailed analysis is followed, which focuses on the traditional facets of motivational beliefs such as opinions, judgments, values, learning motivation and goal orientation that students hold about objects, especially on learning goals, selfefficacy, beliefs about effort and effect of motivational beliefs on learning thereof. Result shows that on one hand principles of motivational beliefs have their origins in the theory of selfconcept develop through the years. On the other hand, they exert prominent effect on youngsters' school learning.
\end{abstract}

Keywords-motivational belief; goal-orientation; self-efficacy; effort; school learning

\section{Motivational BeliEFs AND LEARNING CONTEXT}

Motivation is the combination of desire, values, and beliefs that drives individual to take action. Motivational beliefs refer to the opinions, judgments and values that students hold about objects, events or subject-matter domains. They include intrinsic and extrinsic goal orientation, task value, control beliefs, self efficacy of learning and performance and test anxiety[1]. Learning motivation, which is defined as the internal power that drives individual to learn, is the most powerful driving force for students' learning, such as aquairing of high efficiency of learning, good maks of learning and high expectancy of success etc. with enhancing of students'motivation of learning, the odds of a good outcome students achieved are greatly increased. Judging the quality and depth of the motivation is very important to a student, because it is not only directly related to his(her) commitment, but also directly related to his (her)success. Often students find that they "want" a good academic outcome, but they can't seem to make it happen. Sometimes, this gap occurs when there is a clash between what they are striving for (a good academic outcome/degree) and what they would rather be doing (following a dream of singing in a country-western band). In order to help students to overcome these difficulties in learning context, educators or teachers have to face to such motivational problems that related to students'learning. this is also an important teaching strategy that teachers must grasp in teaching processes. How do teachers provide students with a favorable learning context? What motivational value do students attach to different teaching tasks? In what way do individual differences in goal orientations? or To what extent that motivation originated from learning modulate the possibility of success and failure? These problems especially the main point of motivational beliefs are of great interest among educators and researchers[2]. To answer these questions and create highly motivating learning environments, many teachers try their best to use variety of strategies so as to benefit students. If educators are to be able to improve the motivational efficiency of learning environments and to adjust them to different kinds of students, students' efficacy and effect of learning will be greatly improved. Because it is not the learning situation itself what is crucial, but it's meaning for the students. However, empirical evidence about the effectiveness of educational interventions based on present study does not answer all the questions pointed above. To do them it is necessary, first, to define teaching patterns aimed at enhancing learning motivation; second, to decide which facet of motivational belief could modulate the motivational effect of learning; and third, to study interactions between students' motivational beliefs and learning environments.

In relation to learning environment, research on teaching patterns affecting student motivation has described three principles, which motivate student to strive for understanding and meaningful learning, and not only for passing examination. The three most important principles are as follows: a) Teachers should make their students feel that they act with autonomy, looking for their own goals. b) Teachers should propose objectives and tasks that imply a reasonable degree of challenge and whose achievement has personal significance for the student. c) Teachers should make sure that their students achieve a reasonable experience of progress in order to avoid a decrease in their expectancies of success.

Usually motivation originates from an internal source and is combined with a realistic goal and circumstance, if teachers abide by the three principles practically; a favorable learning context which stimulates students to learn efficiently can be made. The possibilities of getting a good score by students are greatly increased. So with the rapid increasing of teaching content and the continuous variation of learning context, Students are frequently involved in unfamiliar learning 
situations. This may create ambiguity and uncertainty for some students. These provide, on one hand, for some students a good opportunity, and on the other hand these are becoming challenge for other students. Students try to make sense of novel learning situations by referring to their motivational beliefs. Motivational beliefs act as a frame of reference that guides students' thinking, feelings and actions in a subject area. For example, motivational beliefs about mathematics determine which strategies students think are appropriate to do specific tasks. It is noteworthy that a student's beliefs about a domain may be dominantly favorable (optimistic) or unfavorable (pessimistic), in condition of providing a positive or negative context for students learning. Once formed, favorable and unfavorable motivational beliefs are very resistant to change. In fact, Schunk(2005) through his study concluded that "students with greater personal interest in a topic and those who view the activity as important or useful are more likely to use adaptive self-regulatory strategies"[2].

Research in traditional classrooms also suggests that learners' task value beliefs (i.e., the extent to which they find a task interesting, important, and useful) relate positively to their use of self-regulatory strategies (e.g., rehearsal, elaboration, organization)[3]. this put forward some new requirements for teachers, teachers should design their course curriculum to be capable of enhancing the extent to which students value the learning tasks, which can ultimately improve their motivation belief and learning. For doing this, teachers should adopt the following teaching patterns in classroom context:

a) When introducing subjects or activities, teachers' instructions should focus students' attention on learning processes and intrinsic goals so as to help students to develop a precise planning and help them to self-regulate their work. b) When giving information and explanations, Teachers should build a bridge between "the given"------what the student already knows------and "the new"------the idea that the teacher is trying to convey and explain. This objective is better achieved if teachers induce students to positively participate in learning activity. c) When teachers interact with their students, Teachers should induce students to have autonomy-supportive learning. That is, teachers should give more positive reflection and reinforce on students' answer[3].

During development of teaching processes, if these strategies are to be used by the teacher, students' favorable motivation belief can be activated. This will play an important role in achieving a good academic outcome.

\section{UNFAVORABLE MOTIVATIONAL BELIEFS IMPEDE LEARNING}

According to Schunk(2005), Self-regulated learners (SRL) tend to have higher self-efficacy for learning than students with less-adaptive SRL profiles. Bandura(1986) defined selfefficacy as "people's judgments of their capabilities to organize and execute courses of action required to attain designated types of performances" [2]. So hitherto several investigations have studied self-efficacy and its relations to other important variables in classroom contexts. Results have revealed that when compared to their counterparts with lower perceived selfefficacy, efficacious students report more use of cognitive and metacognitive learning strategies. A new study conducted by Nelson and his colleagues(Nelson, Shell, Husman, Fishman \&
Soh,2015) showed that students who adopted maladaptive selfregulatory learning profiles learned less than those who adopted adaptive learning profiles[3].

Self-regulation is defined as that learning what occurs largely from the influence of students self-generated thoughts, feelings, strategies and behaviors, which are oriented toward the attainment of goals. It is usually referred to as academic self-regulation, which is an important source of driving students to learn and making them attain good outcomes. General models of self-regulated learning argue that students who have a learning goal orientation strive to control or manage the aspect of motivation of their learning. They emphasize many of the implementation strategies that reflect students' efforts to control the environment. Similarly, as an important aspect of self-regulated learning, Pintrich (1999) identifies resource management strategies, including efforts to control the environment. At the same time, other types of motivational strategies has been incorporated into models of self-regulated learning, Furthermore, Garcia and Pintrich(1994) discuss students' use of self-handicapping, defensive pessimism as types of motivational strategies. Their research have drawn the conclusion that use of self handicapping strategy has an negative effect on students' learning by influencing their persistence for the academic task[4]

Although prior research exploring motivational beliefs has found that students who exhibit greater task value, greater selfefficacy, and a learning goal orientation tend to display greater use of strategies designed to regulate students' cognitive or metacognitive engagement in academic tasks[5]. Empirical researches described above suggest that students are not motivated to learn in face of failure or frustration. They often experience feeling of learning helplessness or passivity when failure occurs, and the fear of failure often lead to students' avoidance of learning tasks they envolved in. In fact, fear of failure does not automatically lead to passivity or Avoidance. What matters are the motivational beliefs that have been attached to a subject-matter area. For example, some students have dominantly favorable beliefs about mathematics and unfavorable beliefs in relation to language learning. Domain specificity of motivational beliefs implies that a student may be failure-oriented in some domains and not in others. He no longer perceives a relationship between what he can do (his actions) and the outcomes of his actions (success or failure) in the language domain. He feels uncertain, stating that he is unable to perform the tasks well. Students tend to give different reasons for their success or failure in various school subjects and these reasons are consistent with their self-concept of ability in that domain[5]. Children who view poor performance as the result of low ability expect failure to occur again and again. These students experience negative thoughts and feelings during learning.

Negative thoughts that are repeatedly associated with a task or activity become attached to similar learning situations. As such, a whole domain may be categorized as 'too difficult' or 'threatening'. Once these unfavorable motivational beliefs have become part of a student's theory of self, they will be activated again and again, creating doubt and anxiety. Unfavorable beliefs impede the learning process because they direct the learners' attention away from the learning activity itself, 
focusing it instead on their low ability[4]. Even though children's understanding of causality changes with age, their beliefs about the cause of their successes and failures in a particular domain are very resistant to change.

\section{FAVORABLE Motivational Beliefs FACILITATE LEARNING}

Students who have favorable motivational beliefs usually adopt method of Self-Regulated Learning (SRL). SelfRegulated Learning refers to "learning occurs largely from the influence of students' self-generated thoughts, feelings, strategies, and behaviors, which are oriented toward the attainment of goals" [3]. The learning also referred to as academic self-regulation, SRL has been studied in traditional classrooms as a means of understanding how successful students adapt their cognition, motivation, and behavior to improve learning.

In general, investigations have consistently found that students who hold adaptive motivational beliefs tend to use more SRL strategies and, as a result, outperform their lessadaptive counterparts[6]. Pintrich (2000) have given a detailed elucidation on these topics. In fact, the most important assumption shared by nearly all theories of academic selfregulation is the active, constructivist assumption. In Pintrichs' words," learners are assumed to actively construct their own meanings, goals, and strategies...learners are not just passive recipients of information...but rather active, constructive meaning makers as they go about learning" [6]. Besides this, learners can potentially monitor, control, and regulate various aspects of their own cognition, motivation, and behavior, as well as features of the learning environment. This is not to say that learners will self-regulate at all times or in all learning contexts, but that students are self-regulating to the extent that they are cognitively, motivationally, and behaviorally involved in their own learning activities.

As a critical determinant of students' classroom learning and achievement, motivation usually motivated self-regulated students highly to provide greater effort and longer persistence at academic tasks. In cognitive models of motivation, this greater effort and persistence for academic tasks is thought to result mainly from various beliefs, judgments, and perceptions of the students, which is the implications of motivational beliefs. Among these beliefs, the extent to which students value the material or skills they are learning, students perceived selfefficacy,and the goals or reasons students adopt for wanting to complete academic tasks has often been used to understand and explain students' involvement of learning activities.

Task value reflects students' belief about whether the material or skills they are learning are useful, important, or intrinsically appealing. Theoretically, students who view what they are learning as more useful, important, or appealing are likely to engage in a task to provide greater effort toward completing the task, and persist longer at the task than other students. Empirical research in this area has most found a positive relation between students' value for the material they are learning and their choice behavior. Previous study has revealed that students who consider skill in mathematics to be valuable are more likely to take additional math courses in the future compared to students who do not value the material in math[7].

Students perceived self-efficacy for a task, defined as their judgments about their ability to complete a task successfully, has often been used to understand and explain students' choice, effort, and persistence for academic tasks. Bandura(1997) has argued that individuals with greater self-efficacy tend to set higher goals, provide greater effort and persist longer when faced with difficulties than people with lower levels of selfefficacy for the same activity. Similarly, Schunk(1990) have shown that perceived self-efficacy influences many aspects of students motivation. It plays important role in activating students to learn. As one specific indicator of students' effort, self-efficacy can be used to predict students' use of selfregulated learning strategies. Further, self-efficacy can also be tied more directly to students' level of performance on academic tasks.

Goals or reasons students adopt when they engage in academic tasks are helpful for understanding students' learning and achievement in academic contexts(Pintrich \& Strunck 1996). Goasl theory has distinguished two types of goal: learning goal and performance goal. Students adoption of learning goals, or goals focused on wanting to learn and understand the material, has been associated with greater persistence in difficult tasks. They tend to choose more challenging tasks and use more suitable cognitive and selfregulatory strategies (Ames,1992; Anderman \& Maehr, 1994). So students who have a learning goal orientation often adopt adaptive cognitive and self-regulating strategies. Students who have a performance oriented goal usually display more maladaptive outcomes including a preference for less challenging tasks, use of more surface level strategies, and a tendency to give up when faced with difficult tasks[7].

Students are more interested in doing activities for which they think they have the necessary competence, or that they value. Those students who value new skills have established favorable motivational beliefs. The chances are good that they are interested in opportunities to practice these skills. It is important to distinguish such commitment from mere compliance with the teacher-set goals. Many students' complete tasks that they do not value all that much simply because they expect some sort of reward (e.g. high marks, a pass, or social approval). Students, who undertake learning tasks purely for the sake of getting a reward from others, or in order to avoid some penalty, are extrinsically motivated [8]. An activity is generally considered to be intrinsically motivating if external reward is not necessary for students to initiate and continue that activity. Favorable motivational beliefs are attached to the activity itself. Students who are intrinsically motivated will report that they do not have to invest effort and that doing the activity is gratifying. For example, some student says: 'when I am writing poetry or stories for the school bulletin, I lose track of time'. When difficulties arise, these students will persist with the activity because they experience a feeling of self-efficacy[9]. Students who begin the learning process by activating favorable beliefs, particularly masteryorientation, and self-efficacy beliefs need less encouragement from others to get started. Moreover, favorable motivational beliefs draw students' attention to cues in the environment that 
elicit further interest and confidence in their own capacity to do the task. They usually facilitate learning.

\section{STUdENTS' BELIEFS ABOUT GOAL ORIENTATION}

In classroom context, teachers can help students build and maintain their self-efficacy for learning by using various teaching instructional strategies. Although many strategies have been shown to enhance students' self-efficacy and improve motivation and learning in traditional classroom context, two specific strategies for boosting students' selfefficacy in course learning are suggested here.

First, Teachers should help students identify and set challenging, proximal goals. When students set realistic goals, they tend to be more motivated to perform than students who are given no goals or who are simply told to try their best. Furthermore, according to Bandura (1997), students who set a goal are likely to experience an initial sense of self-efficacy in their ability to achieve the goal and are also apt to make a commitment to attempt it. As students' progress, they engage in activities that they believe will lead to goal attainment through attending to instruction, rehearsing information to be remembered, expending effort, and persisting[10].

Goals are only effective motivators if they become internalized to some extent. This is an assumption which is expressed in Deci and Ryan's (1985) important distinction between intrinsic and extrinsic motivation. Usually intrinsically motivated students engage in the learning process because they find it interesting and enjoyable; Whereas extrinsically motivated learners carry out the learning activity in order to gain a reward or to avoid punishment[11]. So highly motivating goals are conscious and help students focus their attention on the learning task (Zimmerman, 2008). Goals also exert their motivational influence through emotional arousal, which is also considered the intrinsic enjoyment derived from learning or as an attitude to the object of learning. A good outcome can be expected in this favorable learning context.

Second, instructors should provide students with timely, honest, and explicit task feedback. Effective feedback from the instructor reveals progress in relation to students' goals, it may help students adjust the level or direction of their effort, and develop students' self-efficacy beliefs as they experience enactive mastery and observe progression toward goal completion. In the course of pursuing their goal-attainment, the way students' orient themselves to learning tasks within a domain is a strong indicator of their engagement and performance. Setting a learning goal refers to the selection of a motivation strategy that fits the actual learning situation. This strategy consists of active attempts on the part of the learner to activate favorable motivational beliefs, to pay attention to relevant cues in the learning environment, and to ignore cues that are distracting from learning. Students who take the time to appraise learning situations in terms of their own goals discover desirable end-states.

Students who learn for the sake of mastering a new skill use more effective learning strategies than students who are ego-oriented[5]. The latter students engage in learning tasks with the intention to demonstrate success (approach egoorientation) or to hide failure (avoidance ego-orientation). The motivation process of mastery-oriented students differs from that of ego-oriented students in many ways. For example, a student shows mastery orientation in relation to the math domain and ego-orientation in relation to language domain. $\mathrm{He}$ can invest effort to learn mathematics because he values mathematics and enjoys improving his math skills. When he meets obstacles while doing math, he often asks himself: 'How can I make it work?' He is not ashamed that others hear about his mistakes. On the contrary, he always volunteers to show his competence of solving math problems. In contrast, he does not want others to find out that he made many spelling and grammatical mistakes in language learning. Because he also values mathematics for different reasons[12]. But for other student who is ego-oriented in math class, she wants to demonstrate success to change other people's opinion about her math ability. She invests effort in math as long as she feels confident that she can find the correct solution. She often gives up when the mistake occurs, because she believes that there is only one correct solution. These beliefs will make her fear that others will use her mistakes as proof of her math ability.

\section{CONCLUSION}

Motivational beliefs described in the paper mainly focus on the students' beliefs, opinions and values and how these motivational beliefs affect learning. Through describing about roles of them played in learning, you may gain insight into the reasons why students are or are not motivated to learn in the context of the classroom. Yet the contents of this paper do not refer to particular curricula or specific age groups. Rather, they refer to genetic aspects of motivated learning that cut across school subjects, grade levels and types of education. The capacity to listen to your students and observe their behavior in the live classroom will help you to inform of what they find interesting, challenging, boring and threatening, and why they have this opinion. Owning knowledge of your students' motivational beliefs will help you to create learning environments that are well suited to their psychological needs.

\section{REFERENCES}

[1] A.J. Matin, School motivation of boys and girls: differences of degree, differences of kind, or both? Austrilian Journal of Psychology, 2004,56, pp.133-146.

[2] D.H.Schunk, Self-regulated learning: The educational legacy of Paul R. Pintrich. Educational Psychologist, 2005, 40, pp.85-94.

[3] T.J.Alonso, and A.Pardo, Assessment of learning environment motivational quality from the point of view of secondary and high school learners. Learning and Instruction, 2006,16,,pp.295-309

[4] J.L.Meece, E.M.Anderman, and L.H.Anderman, Classroom goal structure, student motivation and academic achievement. Annual Review of Psychology, 2006,57,pp.487-503.

[5] D.F.Shell, J.Husman,E.J.Fishman, and L.K.Soh, Motivational and selfregulated learning profiles of students taking a foundational engineering course,Journal of Engineering Education 2015, 104(1),pp.74-100.

[6] A.J. Matin, Building classroom success: Eliminating academic fear and failure. London:Continuum. 2010.

[7] P.Pintrich, The role of motivation in promoting and sustaining self regulated learning. International Journal of Educational Research,31,pp.459-470

[8] P.R. Pintrich, The role of goal orientation in self-regulated learning. In Boekaerts, M.; Pintrich, P. R.; Zeidner, M., eds. Handbook of selfregulation(pp. 451-502). San Diego, CA, Academic Press. 2001. 
[9] C.A. Wolters, H. Rosenthal, The relation between students' motivational beliefs and their use of motivational regulation strategies, Elsevier Science, 2001,pp.801-820.

[10] J. Kormos, T. Kiddle, and K. Csize'r, Systems of goals, attitudes, and self-related beliefs in second-language- learning motivation, Applied Linguistics, 2011,pp.495-516.

[11] B.J.Zimmerman, Goal setting: a key proactive source of academic selfregulation' in D.H. Strunck and B.J.Zimmerman(eds):Motivation and self-regulated learning: Theory, Research, and Application. Lawrence Erlbaum, 2008, pp.267-295.

[12] A.J.Matin and M. Dowson, Interpersonal relationships, motivation, engagement and achievement: Yields for theory, current issues, and practice. Review of Educational Research, 2009,79, pp.327-365. 